\title{
POSSIBILITIES TO IMPROVE ROTARY PARLOUR MILKING EQUIPMENT EFFICIENCY
}

\author{
Maris Mangalis, Juris Priekulis, Mara Mangale \\ Latvia University of Life Sciences and Technologies, Latvia \\ maris.mangalis@inbox.lv, juris.priekulis@1lu.lv,maramangale@inbox.lv
}

\begin{abstract}
The aim of the research was to evaluate the factors influencing the productivity of rotary parlour milking equipment and the possibilities of their correction. Productivity of rotary parlour milking equipment is influenced by three main factors: the number of milking places on the rotary platform, the set rotation speed or the time of one revolution of the platform and cows with longer milking duration. Methodology for theoretical calculation of the cycle of rotary parlour operation according to the statistical indicators of the milk yield of the herd of the corresponding farm has been developed. To test the methodology also experimental research was performed in four farms, where rotary parlours with 32 to 80 milking places are used. The initial data necessary for the research were obtained in the result of timing the milking process and analysing the data obtained from the management on the milking process with MS EXCEL data analysis tool Descriptive Statistics. It has been stated in the research that the operation regimes of rotary parlour milking equipment used in practice and calculated theoretically have slight differences. Therefore, it is necessary to test the method of theoretical calculation additionally in the conditions of operation.
\end{abstract}

Keywords: milking, cows, rotary parlour, productivity.

\section{Introduction}

In the large milk cow farms, where the herd reaches 400-500 animals, rotary parlour milking equipment is recommended [1;2]. Its advantages are comparatively high productivity of work and the possibility to automate the milking operations. Besides, it is possible to have a different number of milking places and location of cows during milking. Nevertheless, the efficiency of this equipment does not always correspond to the data indicated in the technical documentation, as in the conditions of operation it usually does not exceed $90 \%$ of the possible efficiency of work [2;3].

The most important reasons that can reduce the productivity of the milking equipment are related to inadequate organisation of work, maintenance of the milking equipment and repair [3;4]. Besides, the productivity is reduced also by other kinds of interruption of operation of the milking equipment [5;6]. For instance:

1. interruptions of technological nature (cows do not go to the rotary equipment platform);

2. stoppage of the rotary milking equipment caused by cows with longer milking duration.

It is possible to reduce the interruptions by more efficient organisation of work and correct application of mechanical movers [7]. However, the problem of cows with longer milking duration is more complicated. Incorrectly chosen speed of rotation of the platform increases the number of cows that cannot be milked during one revolution, or vice versa, it increases the idle time of the milking equipment $T_{d i k}[6 ; 8]$.

It has been stated in the research $[2 ; 3 ; 5]$ that one of the solutions of this problem that ensures increase in the productivity of the milking equipment or carrying capacity is that cows with longer milking duration are milked in the second rotation that can reach in practice even 8-16\% of the total number of cows to be milked [3].

Still, such approach complicates the construction of the milking equipment and therefore such rotary equipment is very seldom used. The aim of the present research was to evaluate the possibility to increase the efficiency of the rotary type milking parlour selecting rational rotation speed of the platform in order to exclude long time stay of the cows on the rotary platform, as well as to reduce the number of the cows that cannot manage to be milked in one revolution of the platform.

\section{Materials and methods}

Capacity of rotary parlour milking equipment is calculated by formula

$$
W=\frac{3600 \cdot Z_{s l}}{T_{c}},
$$


where $Z_{s l}-$ number of milking places on the rotary platform;

$T_{c}$ - time of one cow milking cycle, s;

$W$ - capacity of rotary parlour, cow $\cdot \mathrm{h}^{-1}$

The formula shows that the productivity of the milking equipment is influenced by two parameters: the number of milking places and the time of one cow milking cycle. The number of milking places depends on the construction of the equipment and it is impossible to be changed during operation. In turn, the length of the cow milking cycle is related to the selection of the optimal rotation speed of the rotary platform and it is characterised by formula

$$
T_{c}=T_{\text {apg }}=t_{u z}+t_{o}+t_{s l}+t_{\text {dik. }}+t_{\text {noie }},
$$

where $T_{c .}-$ total time of one rotation of the rotary platform, s;

$T_{\text {apg }}$ - time of the rotation cycle, s;

$t_{u z}$ - time spent for a cow to enter the milking place on the rotary platform, s;

$t_{o}$ - consumption of time of the milker calculating per one cow, s;

$t_{s l}-$ average duration of milking one cow, $\mathrm{s}$;

$t_{d i k}$ - milking equipment idle time, $\mathrm{s}$;

$t_{\text {noie }}$ - time spent for a cow to leave the milking place on the rotary platform, s.

The milking cycle is shown schematically in Fig. 1.

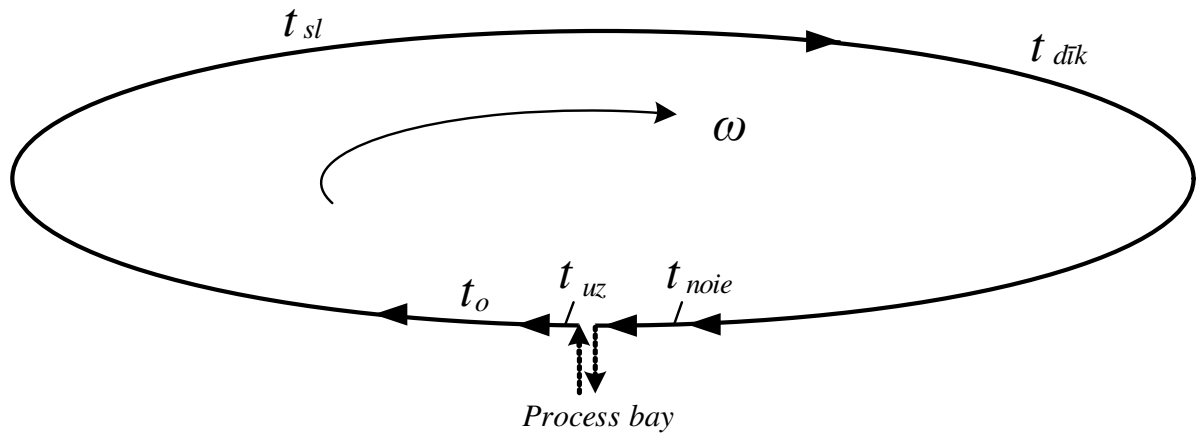

Fig. 1. Scheme of cow milking cycle

Another parameter that should be taken into consideration is the speed of the rotary equipment rotation, $\mathrm{s} \cdot \mathrm{bail}^{-1}$. According to the research of the company DeLaval $[8 ; 9]$ the speed of rotation of the rotary equipment should not exceed $\omega=10 \mathrm{~s} \cdot$ bail $^{-1}$, but in farms with efficient organisation of work it is possible to work with the rotation speed $\omega=5 \mathrm{~s} \cdot$ bail $^{-1}$. Rotation speed $\omega$ shows how many seconds the platform moves through one milking place. For calculation of this parameter the following formula can be used

$$
\omega=\frac{T_{c}}{Z_{s l}},
$$

where $Z_{s l}$ - number of milking places, bail.

During the experimental research it has been found that in every herd the length of milking cows varies according to the normal grouping features [10]. Furthermore, all cows can be divided in three subgroups according to the length of the milking time, Fig. 2.

The first subgroup includes the cows with the milking interval from $t_{\min }$ to $t_{\text {mean }}$. And it comprises $50 \%$ of the total size of the herd. The second group includes the cows with the milking interval from $t_{\text {mean }}$ to $t_{\text {mean }}+\sigma$. It is $34.15 \%$ of the herd. In turn, for the third remaining group the milking time for the cows is from $t_{\text {mean }}+\sigma$ tot $_{\max }$. Its part is $15.85 \%$ of the total size of the herd.

Theoretically it can be assumed that there is a similar grouping according to the length of milking for all cows that are on the rotary platform during milking. Besides, the optimal rotation speed of the rotary platform will be in case, if the cows of group one and group two are milked during one rotation of the platform. In this case, $84.15 \%$ of all cows will be milked slightly faster than the average milking length $t_{\text {mean }}$, but their "riding" length slightly exceeds $\sigma$. Nevertheless, due to long milking 
cows, the number of which is $15.85 \%$ of the total number of cows, the rotary platform will stop and all cows that are on the platform will have to wait. Besides, the average waiting time calculating per one cow will be $\sigma$. Therefore, the summary time of already milked cow "riding" will be approximately equal to the total time of the rotary platform standing for milking the cows with longer milking duration. Though, also the coefficient of the normal grouping asymmetry $k_{A}$ should be taken into consideration. It takes into account that the normal grouping curve can be diverted to the left, i.e. in most cases the cows are milked faster than the average arithmetical length time of milking. Therefore, the time of the rotary platform cycle should be accordingly reduced.

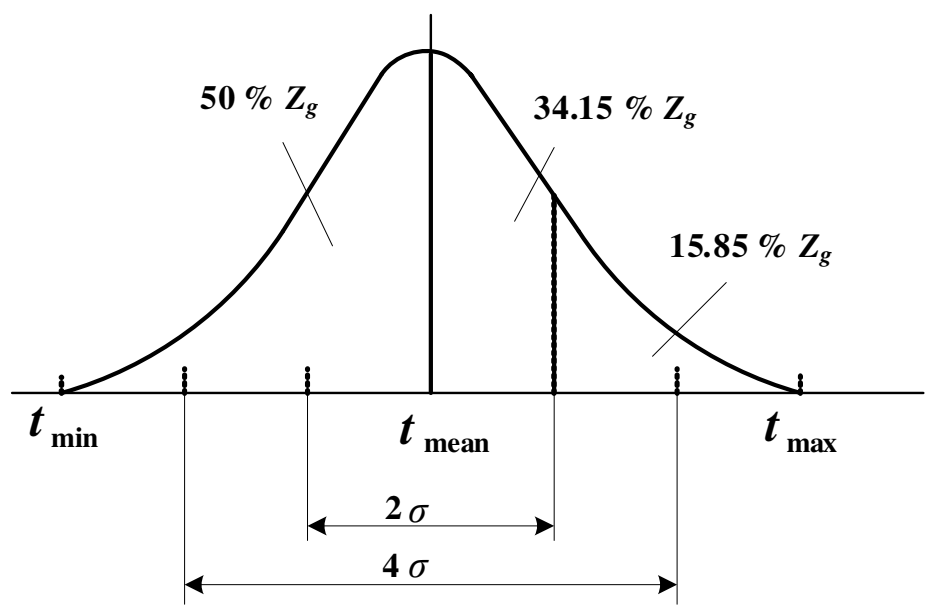

Fig. 2. Scheme of cow milking time grouping for separate herd: $t_{\min }$ - minimal milking time; $t_{\text {mean }}$ - average cow milking time; $t_{\max }$ - maximal milking time; $\mathrm{Z}_{\mathrm{g}}$ - total number of cows in the herd; $\sigma$ - milking time standard deviation

According to these hypotheses the time of one revolution of the rotary platform can be calculated according to the following formula:

$$
T_{c k}=t_{u z}+t_{o}+\frac{t_{\text {mean }}+\sigma}{k_{A}}+t_{\text {noie }},
$$

where $T_{c k}$ - corrected time of one revolution (cycle) of the rotary platform, s;

$\sigma-$ milking time standard deviation, s;

$k_{A}-$ asymmetry coefficient.

To prove the hypothesis experimental research was performed in four farms, Table 1.

Table 1

Characterisation of the milk farms included in the research

\begin{tabular}{|l|c|c|c|c|}
\hline \multirow{2}{*}{ Indicator } & \multicolumn{4}{c|}{ Name of the farm } \\
\cline { 2 - 5 } & A & B & C & D \\
\hline Cow herd size & 600 & 430 & 670 & 2000 \\
\hline $\begin{array}{l}\text { Company producing } \\
\text { equipment }\end{array}$ & $\begin{array}{c}\text { GEA Farm } \\
\text { Tehnolo-gies }\end{array}$ & $\begin{array}{c}\text { GEA Farm } \\
\text { Tehnolo-gies }\end{array}$ & $\begin{array}{c}\text { GEA Farm } \\
\text { Tehnolo-gies }\end{array}$ & $\begin{array}{c}\text { GEA Farm } \\
\text { Tehnolo-gies }\end{array}$ \\
\hline Milking equip-ment & $\begin{array}{c}\text { Auto Rotor } \\
\text { Magnum 40 }\end{array}$ & $\begin{array}{c}\text { Auto Rotor } \\
\text { Magnum 40 }\end{array}$ & $\begin{array}{c}\text { Auto Rotor } \\
\text { Magnum 40 }\end{array}$ & $\begin{array}{c}\text { Auto Rotor } \\
\text { Performer }\end{array}$ \\
\hline $\begin{array}{l}\text { Number of } \\
\text { milking stalls }\end{array}$ & 50 & 36 & 32 & 80 \\
\hline Number of milkers & 2 & 2 & 2 & 4 \\
\hline $\begin{array}{l}\text { Cow mechanical } \\
\text { mover }\end{array}$ & $\begin{array}{c}\text { Cow Mander } \\
640\end{array}$ & $\begin{array}{c}\text { Cow Mander } \\
600 / 700\end{array}$ & $\begin{array}{c}\text { Cow Mander } \\
640\end{array}$ & $\begin{array}{c}\text { Cow Mander } \\
600 / 700\end{array}$ \\
\hline
\end{tabular}

During the research the morning and the evening milking processes were timed, as well as the data stored in the management system DairyPlan C21, Version 5.2. Information on grouping of the milking length was obtained by means of Excel data analysis tool Descriptive Statistics [10]. 
During the research the set rotation time and the time the milker uses for preparation of one cow and application of the milking machine as well as the time necessary for one cow to enter and leave the rotating platform were filed.

\section{Results and discussion}

The milking equipment operation indicators obtained in the research are summarised in Table 2.

Table 2

Rotary milking parlour equipment operation indicators

\begin{tabular}{|l|c|c|c|c|}
\hline \multirow{2}{*}{ Indicators } & \multicolumn{4}{c|}{ Name of the farm } \\
\cline { 2 - 5 } & A & B & C & D \\
\hline Number of milking places & 50 & 36 & 32 & 80 \\
\hline $\begin{array}{l}\text { Set platform revolution time } \\
T_{\text {apg. }} \text { min. } \text { s }^{-1} \text { * }\end{array}$ & $8.0 / 480$ & $7.5 / 450$ & $7.0 / 420$ & $10.0 / 600$ \\
\hline $\begin{array}{l}\text { Time needed for a cow to enter } \\
\text { the platform } t_{\text {uz. }}, \text { s per cow }\end{array}$ & $3 \pm 1$ & $4 \pm 1$ & $4 \pm 1$ & $3 \pm 1$ \\
\hline $\begin{array}{l}\text { Time consumed by the milker } \\
t_{o}, \text { s per cow }\end{array}$ & $28 \pm 5$ & $28 \pm 5$ & $26 \pm 5$ & $23 \pm 5$ \\
\hline $\begin{array}{l}\text { Average milking time } t_{s}, \\
\text { s per cow }\end{array}$ & $402 \pm 138$ & $348 \pm 126$ & $336 \pm 132$ & $396 \pm 156$ \\
\hline $\begin{array}{l}\text { Internal idle time } t_{\text {dikst }}, \\
\text { s per cow }\end{array}$ & 29.2 & 37.8 & 22.4 & 214.7 \\
\hline $\begin{array}{l}\text { Time needed for a cow to leave } \\
\text { the platform, } t_{\text {noie }}, \text { s per cow }\end{array}$ & $15 \pm 3$ & $10 \pm 2$ & $10 \pm 2$ & $16 \pm 3$ \\
\hline $\begin{array}{l}\text { Average length of cow milking } \\
\text { cycle, } T_{c}, \text { s per cow }\end{array}$ & 477 & 390 & 398 & 653 \\
\hline $\begin{array}{l}\text { Set platform rotation speed, } \omega, \\
\text { s. bail }{ }^{-1}\end{array}$ & 9.6 & 12.5 & 13.1 & 7.5 \\
\hline
\end{tabular}

Analysing the data obtained in the research, it can be seen that the cow milking cycle varies from 390 to 653 seconds. The internal idle time is the time when the cow will be milked faster and the milking equipment is removed, while the rotation cycle continues. The bigger the number of the milking places on the rotary platform, the longer the internal idle time, which increases also the total time of the milking cycle. It is additionally influenced also by the ability of the operator to quickly prepare the cow's udder and attach the milking cluster as well as by the speed the cows change places on the rotary platform $[4 ; 11]$.

According to the information that can be found in literature [1] the average time of the milking cycle $T_{c}$ is 498 seconds or 8.3 minutes provided that the average duration of milking of every cow $T_{v i d}$. is 270 seconds or 4.5 minutes. It by approximation corresponds also to the results of the experimental research that are given in Table 2. The cow herd milking parameters obtained in theoretical investigations and the lengths of the cycles calculated by the formula (4) are summarised in Table 3.

Operation indicators calculated in theoretical research

Table 3

\begin{tabular}{|l|c|c|c|c|}
\hline \multirow{2}{*}{\multicolumn{1}{|c|}{ Indicators }} & \multicolumn{4}{c|}{ Name of the farm } \\
\cline { 2 - 5 } & A & B & C & D \\
\hline Average cow milking time $t_{\text {mean }}$, s per cow & 399 & 345 & 338 & 397 \\
\hline Standard deviation $\sigma, \mathrm{s}$ per cow & 136 & 128 & 130 & 156 \\
\hline Asymmetry coefficient, $k_{A}$ & 1.17 & 1.31 & 1.99 & 1.29 \\
\hline Average length of rotary platform cycle, $T_{c k}, \mathrm{~s}$ & 503 & 403 & 275 & 471 \\
\hline${\text { Platform rotation speed } \omega, \mathrm{s} \cdot \text { bail }^{-1}}^{-1}$ & 10.1 & 11.2 & 8.6 & 5.9 \\
\hline
\end{tabular}

Comparing the lengths of the rotary platform cycles that are obtained in the experimental and theoretical research it can be seen that there are no great differences. In farms A and B the theoretically calculated lengths of the cycles are by 3-5\% longer, but in farms C and D - by $28-33 \%$ 
shorter. Nevertheless, in both latter cases the rotary platform rotation speed is in compliance with the recommendations suggested by the company DeLaval - 5-10 seconds calculating per one cow. Therefore, it can be assumed that the operation regime stated in the theoretical calculations is more optimal. However, it should be still tested in the conditions of operation.

\section{Conclusions}

1. Operation efficiency of rotary parlour milking equipment depends on the number of the milking places and the time of one revolution of the platform or the cycle time. The average milking length for the cows from four farms included in the research was $399 \pm 136$ seconds. During this time up to $50 \%$ of all researched cows manage to be milked. If the rotary platform rotation cycle time is increased, also the milking equipment idle time increases and the productivity of operation of the milking equipment decreases.

2. Methodology for theoretical calculation of the rotary parlour operation cycle according to the statistical data of the milk yield of the herd of the corresponding farm has been developed. Comparing the rotary parlour operation regimes used in practice and calculated theoretically slight differences have been discovered. Therefore, for testing the theoretical calculation and possible correction of it additional research is necessary.

\section{References}

[1] Modern Milk Production Farm: Technology, Machinery, Operation./J.Priekuḷa red. Jelgava: LLU, 2012, 240 lpp. (In Latvian)

[2] Edwards J.P., Lopez-Villalobos N., Jago J.G. Increasing platform speed and the percentage of cows completing a second rotation improves throughput in rotary dairies. Animal Production Science 52, 2012, pp. 969-973.

[3] Copeman P.J.A. Achieving efficient throughput in rotary dairies. In 'The Challenge: Efficient Dairy Production'. (Ed. TI Phillips), 1985, pp. 523-552.

[4] Wagner A., Palmer R. W., Bewley J., Jackson-Smith D. B. Producer satisfaction, efficiency, and investment cost factors of different milking systems. J. Dairy Sci.84, 2001, pp. 1890-1898.

[5] Nitzan R., Bruckental I., Bar Shira Z. Stochastic Models for simulating parallel, rotary and sideopening milking parlours. Journal of Dairy Science, vol. 89, No.11, 2006.

[6] Kirsanov V.V. et.al. The Influence of Factors on the Rhythm of Conveyor Milking Machines. 2016. (In Russian)

[7] Mangalis M., Jaundžeikars Dz., Priekulis J. Cow traffic dynamics using mechanical mover International conference "Engineering for Rural Development", May 29-30,2014, Jelgava Latvia, pp. 85-88.

[8] Efficient rotation time. [online][16.02.2019] Available at: https://www.dairynz.co.nz/milking/ rotary/efficient-rotation-time/

[9] Rotary Milking Planning Guide. DeLaval Parallel Rotary PR2100, Brochure.

[10] Arhipova I., Bāliņa S. Statistics in Economics. R. Datorzinību Centrs, 2003, 351 p.(In Latvian)

[11] Firm "GEA Farm Technologies GmbH". Mathematical model "Parlour Economics" 1.2006. 